\title{
¿Quién es el sujeto en la investigación educativa? ${ }^{1}$
}

\section{Who is the Subject in Educational Research?}

\author{
Alicia Gurdián-Fernández ${ }^{2}$ \\ San José, Costa Rica \\ agurdianf@gmail.com
}

Recibido 22 de mayo de 2011 • Acepta 29 de agosto de 2011

\begin{abstract}
Resumen. En este artículo argumento, en primer lugar, que la identidad de quien investiga incide no solo en su forma de investigar, sino también en los procesos de formación de sus estudiantes y, por ende, en la formación de las futuras investigadoras y los futuros investigadores educativos. En segundo lugar, señalo que las instituciones educativas, así como sus docentes, juegan un rol central en la construcción de identidades. En tercer lugar, enfatizo que de esta responsabilidad no se eximen quienes se dedican a la investigación educativa, por lo que les invito a reflexionar sobre: ¿Cuáles son nuestras responsabilidades en el proceso de construcción de identidades? ¿Quién es el sujeto de la educación? ¿Quién es el sujeto de la investigación educativa y en ella?:Cuán inclusivas son nuestras nociones de sujeto educativo y del sujeto empírico?

Mediante el desarrollo y análisis de interrogantes sobre temas como: la relación sujeto-objeto; el sujeto en la investigación educativa; el aporte de la subjetividad; la contribución de la fenomenología; entre otros, argumento que: a) la autobiografía intelectual es un instrumento de gran potencialidad para comprender el tono y la dirección de un proceso investigativo y b) centrar la atención en las personas, en su historia, sus relaciones sociales y su ambiente, como sujetos actuantes y no solo como objetos de estudio es un movimiento epistémico, político y ético, puesto que reconoce la acción del sujeto en el mundo y sobre este. Por último, apelo a que las investigadoras y los investigadores cualitativos no solo deben comprender quiénes son, sino que también deben hacerlo explícito puesto que hay un condicionamiento ético que lo demanda.
\end{abstract}

Palabras claves. Sujeto, identidad, construcción del sujeto en la investigación educativa, relación sujeto-objeto, autobiografía intelectual.

\footnotetext{
1 Este trabajo tiene como punto de partida el Capítulo II (pp. 51-98). La relación sujeto-objeto de Gurdián, A. (2010). El paradigma cualitativo en la investigación socio-educativa. Costa Rica: Editorial de la Universidad de Costa Rica. Así como, la Conferencia Inaugural de la Maestría para Formadores de Docentes de la Educación Primaria o Básica de la Universidad Nacional Pedagógica Francisco Morazán, República de Honduras, que impartí el 17 de octubre de 2008.

2 Catedrática investigadora jubilada de la Universidad de Costa Rica.
} 
URL: http://www.una.ac.cr/educare

Abstract. In this paper I argue, first, that the identity of the researcher has an impact not only in the way she/he invThis article explains, in the first place, that the identity of the researcher not only influences his way to do research, but also the teaching processes and, therefore, training of future researchers. Secondly, it states that schools and teachers play a central role in the construction of identities. Third, this paper emphasizes that those engaged in educational research are not released from this responsibility, so this is an invitation to reflect on the following: What are our responsibilities in the process of identity construction? Who is the subject of education? Who is the subject of educational research? How inclusive is our notion of both the educational and the empirical subjects?

Through the analysis of questions on topics such us: the subject-object relationship; the subject in educational research; the contribution of subjectivity; the contribution of phenomenology; among others, this paper explains that: a) the intellectual autobiography is a great potential instrument to understand the direction of a research process and $b$ ) focusing on people, their history, social relationships and environment, as subjects and not just as objects of study, is an epistemological, political and ethical movement, which recognizes the subject's action in and on the world. Finally, this paper states that qualitative researchers should not only understand who they are, they are ethically obliged to make it explicitly.

Keywords. Subject, identity, subject construction in educational research, subject-object relationship, intellectual autobiography.

La realidad es un mito, una ilusión consensuada que hay que desentrañar, que hay que explorar para saberla parte de nosotros y para sabernos parte de ella. El mito, el gran crimen, es anterior a nosotros, pero en un afán de perfeccionamiento, de querer concretar lo abstracto, de querer objetivar la realidad hemos caído en el vacío de la realidad, el mundo es desconocido y esa es su naturaleza, es ambiguo y cambiante, cualquier esfuerzo por limitarlo traerá graves consecuencias, tales como las que vivimos. Necesitamos un cambio de visión, una nueva forma de observar, ya no sirven los espejuelos mecanicistas, es hora de un punto de vista diferente que acepte la incertidumbre como el principio, como el fin (...)

El mito de la realidad (Chavarría-Rojo, 2006, párr. 1)

\section{A manera de introducción}

Inicio invitando a quienes se interesen en la temática de este artículo a cuestionarse:

I. ¿Quién soy yo? ¿Cuál es mi identidad? ¿Cómo influye esta en mi forma de ver el mundo? ¿Cómo influye mi historia de vida en lo que me interesa investigar o estudiar?

¿Cómo podemos formar estudiantes, profesores e investigadores, transformadores y críticos, si ellas y ellos, a su vez, forman parte de un sistema extenso de dominación y control, tanto nacional como mundial?

II. Espero no equivocarme al asumir que todas las personas quienes lean este artículo estén, de una manera u otra, familiarizadas con el término currículo. Sin embargo, considero pertinente hacer las siguientes aclaraciones. ¿Por qué apelo al concepto currículo?, ¿cómo se relaciona con la temática a la que nos convoca este artículo?

Es indiscutible que la cuestión central y básica de cualquier teoría del currículo es determinar cuál es el conocimiento, así como cuáles son las actitudes, cuáles son las habilidades o destrezas y 
cuáles valores son los que se deben enseñar o reforzar. Decidir qué se debe enseñar es la cuestión central. ¿Qué es lo que ellas o ellos - estudiantes- deben saber, deben aprender? ¿Qué conocimientos o saberes se consideran válidos o esenciales para que se les incluya en determinado programa, pensum, plan de estudio o currículo? ¿Quién o quiénes toman la decisión sobre cuál conocimiento es válido de enseñar y cuál no lo es? ¿Cuál es el conocimiento que el estudiantado debe aprender?

De acuerdo con Da Silva (2001), en la fundamentación de las diversas teorías curriculares hay una cuestión implícita de "identidad" o de "subjetividad", por ejemplo, desde la perspectiva post-estructuralista podemos afirmar que el currículo es también una cuestión de poder. Puesto que en la medida en que "alguien" define lo que debe ser el currículo, el plan de estudio, el pensum o un programa de estudio o un programa de un curso, esta decisión no es ajena a las cuestiones del poder, porque privilegiar un tipo de conocimiento ${ }^{3}$ sobre otros significa valorar y seleccionar unos contenidos, habilidades o destrezas en lugar de otros. ¿Por qué privilegiamos ciertos autores, libros o artículos, sobre otros o por qué ciertos enfoques, métodos, prácticas o actividades en lugar de otras? En síntesis, tener como meta o ideal, entre las múltiples posibilidades, construir cierto tipo de identidad o subjetividad, es una cuestión de poder. Dichas decisiones están en el centro de un territorio en disputa que preferimos, conciente o inconcientemente, ignorar. El mismo autor afirma que hoy en día y de manera menos inocente que antes:

El currículum tiene significados que van mucho más allá de aquellos a los que las teorías tradicionales nos confinaron. El currículum es lugar, espacio, territorio, relación de poder, (...) trayectoria, viaje, recorrido, autobiografía, propia vida, forja de identidad, texto, discurso, documento. El currículum es documento de identidad. (2001, p. 187)

Vislumbro de inmediato, haciendo mías las palabras de Diker y Terigi (1997) el siguiente reto:

¿Cómo transformar la escuela moderna concebida hace trescientos años, en una institución que responda a las necesidades de un mundo globalizado, de una cultura "mass mediática"4 de unos niños [y niñas] que sobre muchas cosas saben más que nosotros, de un mercado de trabajo flexibilizado cuyas demandas formativas mutan constantemente?

¿Cómo respetar las diferencias culturales a través de una institución cuya estructura es profundamente homogeneizante ${ }^{5}$ ?

¿Cómo formar a nuestras y nuestro estudiantes para el ejercicio ciudadano en esta era en que impera la política mediática?

3 Entiéndase conocimientos en su sentido amplio e inclusivo, pues tal y como ya se aclaró anteriormente este incluye las actitudes, habilidades o destrezas y valores, así como una forma de ver el mundo, de ver la sociedad y de ver al ser humano.

4 Este tipo de cultura lejos de eliminar la cultura escrita y oral, lo que hace es nutrirla de nuevas perspectivas y, dado que su uso y consumo, es multidimensional, propicia la hiper-estimulación y la multi-sensorialidad. Se recomienda consultar a: Ferres, J. (2000). Educar en una cultura del espectáculo. Barcelona: Editorial Paidos.

5 Foucault huye de las identidades impuestas y estandarizadas, de las uniformidades producidas desde el discurso homogeneizante del poder, donde todas y cada una de las personas cumplimos un papel y desarrollamos una función. Es urgente, junto con él, reivindicar la contradicción, ya que con ella la identidad se reivindica como crisol de identidades. 
¿Cómo confiar en el sentido de lo que enseñamos si las certezas científicas y la confianza ilustrada en el progreso indefinido del conocimiento están profundamente cuestionadas?

III. Si aceptamos que la construcción de identidades en una sociedad es un tema de importancia central: ¿Cuál es el lugar que ocupan nuestras escuelas, nuestras universidades, en la construcción de identidades? ¿Cuál es el lugar que ocupa el conocimiento en este proceso de construcción? ¿Cuál es la responsabilidad de quien educa en la construcción de identidades? ¿Cuáles son las funciones, deberes y responsabilidades de quien hace investigación educativa en el proceso de construcción de identidades? ${ }^{6}$

En consecuencia, ¿quién es el sujeto de la educación? ¿Cuán inclusiva es la noción de sujeto educativo? Cuán cercana o lejana es la noción de sujeto, si aún cuando hacemos referencia al "sujeto empírico", no consideramos el problema sobre el que Fonseca nos interpela:

(...) "el sujeto empírico" es particularísimo y tiene un rostro visible, se trata de un cierto sujeto masculino (ni siquiera incluye a todos los hombres), bien posicionado en la sociedad, individual, "racional", "sano", blanco, adulto (ni niño, ni joven, ni viejo) y más o menos libre.

Con variaciones de ropaje este referente y su correspondiente abstracción han configurado los grandes relatos de la cosmovisión occidental para explicar el sentido de la realidad y hasta para soñar sus utopías. (Fonseca, 2005, p. 95)

Ahora bien, la misma autora lanza un segundo reto: ¿Cómo "plantear la posibilidad de un conocimiento no sexista y crítico, que relativice los productos de la ciencia (conceptos, leyes y teorías) como creaciones del entendimiento y la sensibilidad del ser humano (hombre o mujer) y no como verdades inmutables"? Fonseca (2005, p. 96)

Las interrogantes hasta aquí planteadas disparan, desde mis propias búsquedas e inquietudes, una problemática a la que me atreveré a dar, sin pretender ser exhaustiva, algunas respuestas.

\section{2. ¿Cuál es mi punto de partida?}

2.1 Las prácticas educativas y docentes son formas de transmisión, reproducción y espacios de resistencia de saberes, conocimientos, valores prácticos y concepciones de la realidad como procesos importantes en la formación de sujetos, en la formación de personas.

2.2 Lo que cambia en quien (sujeto) aprende son las representaciones sociales mediante las cuales identifica lo real, interpreta el mundo y fija sus posiciones en el mismo mundo.

2.3 Las teorías más recientes se orientan a establecer con claridad el discurso pedagógico, como la reflexión pertinente y rigurosa de las prácticas sociales de la educación a partir

\footnotetext{
La construcción de identidades implica varias dimensiones de análisis, tales como los espacios institucionales de la socialización cultural, a saber: el universo familiar, el universo escolar y el universo mediático. El sujeto es interpelado a partir de las concepciones pedagógicas sustentadas no solo en el ámbito institucional de la escuela, sino en otros espacios que comparten la tarea de los procesos socializadores: la familia, y los medios masivos de comunicación. Sin embargo, me interesa centrarme en la responsabilidad de las instituciones universitarias, específicamente en el cuerpo docente, responsable en la construcción en el sujeto educativo y más puntualmente en la construcción del sujeto de la investigación educativa y en ella.
} 
de la docente o el docente, considerados ambos como sujetos de saber pedagógico y como sujetos de políticas públicas. El saber pedagógico se constituye, entonces, en objeto de estudio investigativo y académico.

2.4 La construcción del sujeto no es solo un problema conceptual, sino que también es un problema ético y político, problemas centrales en un proyecto educativo y, por ende, en la investigación educativa.

2.5 Toda práctica educativa es en sí productora de sujetos, a partir de la mediación de otros sujetos.

2.6 En toda investigación subyace un componente ideológico, político y ético.

2.7 Es urgente reconocer que no existe neutralidad científica, ni en el modo de producción del conocimiento ni en los resultados que de él se derivan.

2.8 El enfoque positivista de la investigación ha bloqueado la capacidad de comunicación y de producción de conocimientos.

2.9 El sujeto, como constructor y productor de su mundo, elabora, reelabora y desecha cada día construcciones de ese mundo.

2.10 El carácter esencialmente activo de quienes devienen en sujetos en la investigación educativa, como constructores y constructoras de su propia realidad, les otorga el derecho a participar en todo el proceso investigativo.

2.11 El sujeto que me interesa, que me cautiva es EL SUJETO PERSONA, en relación con el mundo en donde vive e interactúa con otras personas para transformar el mundo.

\section{3. ¿De qué hablo cuando me refiero a la relación sujeto-objeto?}

La relación entre sujeto y objeto que establecen las diferentes matrices epistémicas o paradigmas investigativos determina el modo de conocer e interpretar la realidad. Por ello es necesario acercarse críticamente a los conceptos de dicha relación.

El sujeto es el elemento de la relación sujeto-objeto que, en su acto de conocer, recibe las imágenes del mundo; las procesa, interpreta y explica a través del lenguaje, a partir de lo cual genera una valoración o juicio. El sujeto es acción, es un ser activo y creador, que desborda los límites de los sentidos en la infinita riqueza de la imaginación.

El objeto es el otro elemento que compone la díada de esta relación. Se entiende por objeto de investigación todo sistema del mundo natural o material o de la sociedad, cuya estructura, por ejemplo, presenta al ser humano una necesidad por comprender, interpretar, explicar o transformar, es decir, un tema o problema de investigación.

El objeto es el sub-sistema donde el tema o problema existe y se desarrolla. Recordemos que el tema o problema está contenido en el objeto. Todo objeto de investigación, a su vez, "dialoga" con su medio o contexto. Por ello es importante no confundir el objeto de investigación con el tema o problema de investigación.

Otro elemento imposible de soslayar es la realidad, de ahí la importancia de hacernos, entre otras, estas preguntas: ¿Qué es la realidad? ¿Cómo se concibe la naturaleza de la realidad? ¿Cómo concibo Yo la realidad? ¿Cuál es la diferencia entre la realidad empírica u objetiva y la realidad epistémica? 
La realidad empírica puede tener una existencia independiente de un sujeto que la conozca. La realidad epistémica, por el contrario, necesariamente requiere de un sujeto cognoscente para su existencia.

El sujeto está influido por una cultura y unas relaciones sociales específicas. Por consiguiente, la realidad epistémica depende, para su definición, comprensión y análisis, del conocimiento de las formas de percibir, pensar, sentir y actuar, propias de sujetos cognoscentes y de sus propias historias de vida. En síntesis, la realidad epistémica se define a partir del sujeto y su relación con el objeto.

Bien sabemos cuán difícil es elaborar una definición teórica, puesto que el sujeto que conoce la realidad y trata de aprehenderla, al entrar en contacto con ella, no puede "deshacerse" de sus expectativas, creencias, prejuicios y concepciones del mundo físico y social. No podemos intentar siquiera elaborar un concepto sin que nos acompañe nuestra historia de vida cargada de creencias, de actitudes, de experiencias, de tabúes, de fobias, de amores y también de desencuentros. Me referiré entonces a tres maneras de ver la relación sujeto-objeto.

A. Esta relación bien podría abordarse como lo pretendió el positivismo: representando el objeto sin que la acción del sujeto incida en la relación. Esto es lo que la modernidad ha "entronizado" como el fundamento de la "objetividad". Ello equivale a anular-distanciar al sujeto de la relación. Al respecto, Fonseca (2005, p. 91) certeramente afirma que "La pretendida necesidad de objetividad total, tan cara a la modernidad, des-humaniza al sujeto, es decir, lo descarna, le roba su cuerpo y su historia, lo saca de su espacio y su tiempo, lo convierte en una abstracción”. Es así como el papel del sujeto se reduce a ser frontera del objeto cognitivo, ya sea para su indagación o experimentación.

B. Otra forma de ver la relación sujeto-objeto es estableciendo el peso determinante en la conciencia del sujeto y opacando la incidencia del objeto. Esta posición establece un culto a la "subjetividad", lo que equivale a sacar al objeto de la relación. Su papel se ve reducido al de un "fenómeno de conciencia", apto para constituirse en una unidad cognoscitiva o valorativa en el sujeto. Esta perspectiva propone, para el análisis, las categorías de sujeto, subjetividad y significación, cuya mutua filiación se encuentra en los conceptos de interioridad y vivencia. Desde el punto de vista del conocimiento, lo que interesa desarrollar es aquello que en las percepciones, sentimientos y acciones de los sujetos actuantes se considera como pertinente y significativo. La resultante es que los esfuerzos investigativos se focalizan en descubrir esa realidad, aún para los propios sujetos actuantes, porque como lo afirmara Hegel: "Lo conocido por conocido, no es necesariamente reconocido".

C. Cabe aún una tercera perspectiva: la interpretación de sentidos desde "la otredad", esto quiere decir que se penetra desde el interior en esa relación sujeto-objeto. El sujeto está inmerso en el objeto, es decir, es parte integrante de una totalidad. El sujeto puede conocer, valorar o transformar como "objeto" de cognición, de valoración o de transformación sin dejar de pertenecer a esa totalidad ${ }^{8}$. Así, ni el sujeto ni el objeto se excluyen de la relación epistemológica.

\footnotetext{
El término "vivencia" utilizado por Dilthey, implica la experiencia inmediata de la vida. En consecuencia, se contrapone: el conocimiento de las ciencias físico-objetivas. El a priori del mundo de la vida: fundamento fenomenológico de una ética de la ciencia y de la técnica.

8 Esto se conoce como "circularidad hermenéutica objetividad-subjetividad".
} 
Para lograr esa "penetración desde una otredad en el interior" en la relación sujeto-objeto se necesita acceder a ella desde una instancia mediadora que, sin "separar", pero sin reducirse a ninguno de los dos polos de dicha relación (el objeto o el sujeto), los contenga dialécticamente a ambos. Esa instancia mediadora es aportada por la praxis humana-social e histórica- en sus diferentes contextos. En la praxis siempre se combinan e integran los aspectos subjetivos y objetivos del quehacer cotidiano de los seres humanos.

Esta perspectiva (hermenéutica) nos permite afirmar que solo mediante los contextos de praxis interpersonal, social, histórica y política, es como un sujeto y un objeto de esa praxis logran establecer un contacto cognitivo y valorativo. En síntesis, desde la hermenéutica, las condiciones más importantes para producir conocimiento son:

- recobrar la subjetividad como espacio de construcción de la vida humana,

- reivindicar la vida cotidiana como escenario básico para comprender la realidad socio-cultural y

- proponer la inter-subjetividad y el consenso, como medios para construir el conocimiento de la realidad.

\section{4. ¿Cómo incide lo aquí planteado en quienes investigan en educación?}

Para incorporar lo planteado en la práctica investigativa cotidiana se requiere de una aproximación cognitiva, una aproximación actitudinal y una aproximación política, por tanto, inicio con la re-visión de las siguientes premisas.

1. En los diversos procesos socio-educativos enfrentamos una malla espiral determinada por subjetividades y objetividades sociales. Esta malla es compleja, multidimensional y dinámica. En consecuencia, para penetrar "desde su/la otredad" en el interior de dicha malla, sin escinidir ninguno de los polos de la díada sujeto-objeto, es necesario hacerlo desde el componente socio-cultural, donde tales objetividades y subjetividades sociales se combinan, sin subordinarse una a la otra, desde la praxis interpersonal, social, política e histórica.

2. La experiencia humana tiene un triple asidero: universal -como especie-particular-como parte de una cultura y sociedad determinadas- y específico -como realidad única e irrepetible-, perteneciente a un momento de la historia social y personal.

3. En la episteme de la modernidad se define el conocimiento como el producto que se obtiene del proceso de apropiación de los datos ofrecidos por el objeto y las acciones u operaciones del sujeto. Sin embargo, en la episteme de la posmodernidad, el conocimiento se define como el proceso que se construye y re-construye, cotidianamente, a partir de la inter-subjetividad entre sujetos a propósito del objeto, produciendo estructuras mentales que fluyen y crean cambios cualitativos en el entorno, aceptando a su vez que la realidad está condicionada por el contexto político, económico, social, cultural e histórico.

4. Desde la perspectiva de la comprensión de las posibilidades de conocimiento de la realidad se acepta la existencia de múltiples visiones con diversos grados de comprensión y validez sobre dicha realidad. En este sentido, es particularmente importante reconocer que el conocimiento de la 
realidad supone no solo su descripción operativa, sino ante todo la comprensión del sentido de la misma por parte de quienes la producen y la viven. Es pertinente, en este caso, plantearnos preguntas tales como: ¿qué significa este mundo "social" para mí como investigadora o investigador?, ¿qué significa este mundo "social" para las personas participantes o sujetos actuantes, que también asignan un sentido a su actuar en el mundo?'

5. Del libro La construcción social de la realidad de Berger y Luckman (1987), se desprende que la realidad social no es una cosa que exista con independencia del pensamiento, de la interacción y del lenguaje de los seres humanos. Por el contrario, es una realidad que se materializa a través de esos tres medios: pensamiento, interacción y lenguaje.

6. Aceptar que la realidad social y la realidad educativa son construcciones cotidianas implica que debemos estudiarlas dialécticamente ya que, obviamente, la educación y la sociedad se definen, se construyen y se transforman la una a la otra constante y dinámicamente y, en este proceso, el sujeto construye revisa, re-construye y desecha las construcciones y significados subjetivos que elabora sobre ese mundo. Dichas elaboraciones simbólicas se expresan y comparten mediante el lenguaje, producto del encuentro de subjetividades.

\section{5. ¿Quién es el sujeto de la investigación educativa?}

Se impone referirme al concepto realidad antes de interpelar al sujeto de la investigación educativa, específicamente a quien investiga, pues tratamos con una realidad abierta, impredecible y en permanente movimiento.

\section{1 ¿Realidad-realidades?}

¿Cómo es posible continuar relacionándonos en el mundo y con este como si la realidad tuviera una existencia de "objeto", de algo externo a nosotras y nosotros como conocedores? ¿Cómo es posible continuar precibiendo la realidad como algo ajeno, distante e independiente del acto mismo por el cual la conocemos o pretendemos conocerla? No es necesario que neguemos la existencia objetiva de lo real: nada nos obliga a llegar hasta ese punto; pero los elementos de que disponemos nos obligan a poner esa objetividad entre paréntesis y a proceder consecuente y consistentemente.

Es preciso abandonar la idea heredada de que somos como una máquina conocedora que refleja y valida el mundo externo y que lo describe recurriendo a rasgos o imágenes preconcebidas e impuestas.

Todo ser humano es un ser conocedor que dispone de un sistema nervioso que se relaciona activamente con su contexto o medio. El acto de conocer es el de actuar ${ }^{10}$ en la realidad -enactuar la realidad-participamos en este como un acto propio de nuestra condición de seres humanos, del ser y hacernos que nos corresponde como entidades auto-productoras.

\footnotetext{
$9 \quad$ Al formular así nuestras preguntas, dejamos de aceptar ingenuamente el mundo social y sus idealizaciones y formalizaciones como ya elaboradas e incuestionablemente provistas de sentido, y emprenderemos el estudio del proceso de idealización y formalización como tal, la génesis del sentido que los fenómenos sociales tienen para nosotros tanto como para los actores, el mecanismo de la actividad mediante la cual los seres humanos se comprenden unos a otros y a sí mismos (...). Schutz (1974, p. 20) 
De lo anterior se desprende que las nociones que están en el centro de ese nuevo paradigma, que se preconiza, para conocer-comprender el mundo de hoy son, entre otras: el sujeto, el cambio del supuesto de la objetividad al supuesto de la subjetividad, los métodos y procedimientos para investigar, conocer e interpretar la realidad.

\section{2 ¿Qué aporta la subjetividad de quien investiga al proceso?}

La observación científica no es pura ni objetiva, sino que lo observado se inserta dentro de una matriz o marco referencial, constituido por los intereses, valores, actitudes y creencias de la persona que investiga, dándole un sentido subjetivo a lo observado.

Esta afirmación deja en suspenso las clásicas polaridades de sujeto-objeto, abriendo de par en par la puerta a la subjetividad y esto nos lleva hacia un ser subjetivo, un ser persona, que únicamente se comprende en la convivencia con las otras personas que también poseen su propia matriz de valores, actitudes, intereses y creencias.

Así, sujeto y objeto son dos términos que están en constante movimiento, oponiéndose, comprometiéndose, separándose, modificándose en un movimiento que se inicia por la voluntad del sujeto que desea el conocimiento, pero que en realidad continúa repetidamente, hasta adquirir un conocimiento cada vez más completo y profundo sobre el tema o problema. Sin embargo, cuando el tema por estudiar son grupos humanos, es decir, otros sujetos, estos dejan de ser objeto y se transforman en sujetos actuantes en el proceso investigativo. Vemos entonces cómo se tambalea el supuesto de objetividad.

El supuesto de la objetividad garantizaba la distancia entre sujeto y objeto, afirmando la neutralidad de tal forma que los resultados de una investigación educativa fueran "válidos y confiables". El objeto no podía ser "contaminado" por el sujeto. Es decir, en el objeto no podía quedar la más mínima huella del sujeto. Siguiendo esta línea, para lograr un conocimiento "objetivo" quien investiga debería despojarse de toda su carga de valores, deseos, intereses o prejuicios. Pero esto sería convertirse en una especie de tabula rasa, un ser sin historia, ni formación, ni experiencia, libre de toda preocupación psicológica por la naturaleza del conocimiento que va a obtener. Y esto, lo sabemos, nunca va a ser del todo posible, pues el sujeto de la investigación es siempre un sujeto humano, un sujeto con historia.

\section{3 ¿Qué nos dice el supuesto de la subjetividad?}

De acuerdo con este supuesto también conocido como supuesto de la reflexividad, el sujeto se acerca al objeto, no está distanciado del objeto, lo aprehende y lo modifica y, a su vez, es modificado por el objeto. En toda investigación siempre quedan huellas del sujeto en el objeto. Todo objeto es producto de la acción o actividad objetivizadora del sujeto, en otras palabras, de la persona a cargo del proceso investigativo y de quienes participan en él.

Recordemos con Miglianelli (s. f.), que la visión segmentada del mundo debe ser desechada puesto que "(...) la vida en el planeta, no es una cuestión de jerarquías, sino de red, donde un eslabón dañado, afecta al conjunto" (párr. 3). 


\section{URL: http://www.una.ac.cr/educare}

A partir de esta "ecología social" puedo describir e interpretar el mundo de una manera sistemática y desde una perspectiva amplia -holista y ecológica-, posición que no nos ofrece ninguna de las concepciones reduccionistas ${ }^{11}$ del mundo, ni aisladamente ninguna de las diferentes disciplinas. Un pensamiento ecológico sería, entonces, un pensamiento relacional, dialógico, en el cual se indica que todo lo que existe, co-existe y que nada existe fuera de sus conexiones y de sus relaciones (esto no se refiere solo a la naturaleza, sino también a la cultura, la sociedad, la mente y el individuo). El pensamiento ecológico es, por lo tanto, relacional, abierto y trae consigo la idea de movimiento, de flujo energético continuo, de propiedades globales, de procesos autorreguladores, auto-organizadores, muestra la existencia de un dinamismo intrínseco que traduce la naturaleza cíclica y fluida de esos procesos. Esta posición suscribe una visión de la realidad-realidades, que va de la mano con una transformación fundamental de mi yo -como persona- de mi modo de pensar, de mi modo de percibir, de mi modo de valorar y de mi modo de actuar.

El sujeto-persona actúa y construye en el mundo donde vive: el "mundo de la vida”, que es la fuente que origina y rige el modo general de conocer, propio de un determinado período histórico-político-cultural y en una geografía específica.

En síntesis, consiste en el modo propio y peculiar, que tengo yo -COMO PERSONApara asignar significados a las cosas y a los eventos, es decir, es la capacidad y forma que tengo YO-PERSONA para simbolizar la realidad.

Esta capacidad de simbolizar la realidad está compuesta por un sistema de formas de pensar, generalmente inconsciente, que constituye "la vida misma" y "el modo de ser", y da origen a una cosmovisión, a una mentalidad e ideología específicas, a un paradigma, a cierto grupo de teorías y, en última instancia, a métodos y técnicas para investigar la naturaleza de la realidad-realidades, ya sea natural, "social" y, dentro de la realidad social la realidad educativa.

Esta posición nos convoca a desarrollar una nueva actitud investigativa y procesos de pensamiento que permitan comprender mejor al sujeto, al sujeto-persona, a las personas actuantes en el proceso, su identidad, su historia de vida, sus grupos, sus redes, sus vínculos, sus sistemas de información y de comunicación. Solo de esta forma podremos develar cómo las personas construyen conocimiento sobre la realidad social y educativa. Más aún, esta posición nos arrastra a comprender-NOS, a comprender-ME, a conocer-ME como sujeto, con mi identidad, historia de vida, intereses, creencias, prejuicios, tabúes, preferencias...

Centrar la atención en las personas, en su historia, sus relaciones sociales y su ambiente, como sujetos y no solo como objetos de estudio, es un movimiento epistémico, puesto que reconoce la acción del sujeto sobre el mundo y que la construcción del conocimiento es histórica, dialéctica y colectiva.

11 Ni las ego-centristas, ni las etnocentristas, ni las socio-centristas y menos aún las sexistas. 
Descentrar al objeto y retomar al sujeto es un movimiento paradigmático epistémico, que nos lleva a preguntarnos sobre las condiciones que hacen posible la reflexión, la seguridad, la confianza, la praxis, la organización y selección de la información; sobre las destrezas y las aptitudes que las personas ponen en juego durante las relaciones inter-subjetivas, incluyendo los aspectos éticos, afectivos y actitudinales que intervienen e influyen en dichas relaciones. Al descentrar al objeto y retomar el sujeto, se inicia un proceso efectivo para establecer relaciones simétricas, horizontales y modificables que faciliten el diálogo en una ecología sin direcciones ni sentidos únicos y, así, reconstruir el poder.

\section{6. ¿Qué nos aporta la fenomenología?}

La fenomenología nos enseña que es preciso comprender y sentir con la otra persona para aprehender la lógica y la ontología propias de su mundo. Comprender al otro -la otra persona- es practicar la empatía, proceso que no solo nos revitaliza, sino que también nos posibilita comprender, explicar, respetar y valorar a la otra persona. Esto implica respetar la alteridad ${ }^{12}$, así como los derechos culturales, entre otros, de las otras personas.

La relación de alteridad se refiere a la capacidad ética de reconocer la legitimidad de la otra persona en tanto que es otra. Y, ¿quién es esa "otra persona”? Para Magendzo (2004, párra. 3) “(...) el conocimiento del Otro remite al Otro no como 'instrumento', como alguien que se pueda utilizar con fines propios, que pueda hacerse visible o invisibilizarse arbitrariamente" (...). Y para Gadamer (1976, párr. 3 “(...) el conocimiento del Otro es el de 'apertura', cuando uno se deja hablar por el Otro (...)".

Pero, ¿qué llevamos al investigar en nuestra mochila de viaje?

Los seres humanos en sociedad son sujetos actuantes.

$>$ El conocimiento se construye socialmente.

$>$ Todos los seres humanos reflexionan e interpretan el mundo independientemente de su función productiva.

$>$ El conocimiento no es neutral ni separable de la práctica, puesto que "no hay interés teórico que esté desvinculado de intereses prácticos (...)" (Girardi, 1977, p. 101)

$>\mathrm{La}$ autocrítica forma parte del proceso investigativo. Quienes investigan no están libres de intereses y tienen puntos de vista sesgados.

> La aspiración del conocimiento es la emancipación: la toma de control de nuestra propia vida, tanto personal como colectiva. Por tanto, los saberes que interesan son aquellos que son importantes para satisfacer igualitariamente las necesidades humanas más auténticas.

$>$ El conocimiento no es solamente racionalidad, sino que incluye la experiencia vital.

> “Nuestra visión de la realidad depende del lugar social que ocupamos".

2 Este término se aplica al descubrimiento que el "yo" hace del "otro", lo que hace surgir una amplia gama de imágenes del "otro", del "nosotros", así como visiones del "yo". 


\section{7. ¿Por qué es imperativo elaborar y reflexionar sobre nuestra autobiografía intelectual?}

Que la investigadora y el investigador educativos, como sujetos actuantes en el proceso investigativo, comprendan e incorporen la construcción de su autobiografía o viaje intelectual como práctica investigativa trasciende su compromiso ideológico y político puesto que:

Comprender y explicitar quién soy, qué es lo que sé, qué es lo que siento y quiero, es algo ético.

Nuestros sentimientos, verdades, creencias, principios, prejuicios e ideas también son datos y, por lo tanto, son una clave para comprender la naturaleza del ambiente social, educativo y cultural no solo en el que vivimos, sino también sobre el que queremos estudiar o investigar.

Elaborar nuestra autobiografía o "viaje intelectual" es una provocación -una invitación a reflexionar-, a ser auto-críticas y auto-críticos, SOBRE MI PERSONA, mi vida, mi formación, mis gustos, mis preferencias, mis sentimientos, mis prejuicios, mis pasatiempos, es decir, sobre mi historia de vida y mi experiencia en el mundo.

La autobiografía intelectual es un instrumento que trasciende el propósito de recoger información y que, por su carácter, tiene una gran potencialidad para comprender el tono y la dirección del proceso de investigación.

Les invito entonces a realizar un viaje -su propio viaje- un viaje introspectivo, reflexivo y analítico. Para ello es preciso que reflexione SOBRE SU PERSONA, su vida, su familia, su formación, su historia de vida, su experiencia... Las siguientes interrogantes son una guía, una invitación para iniciar una narración reflexiva y crítica sobre su vida y sus experiencias...La meta es contestar-SE:

¿Quién soy yo?

¿Cuál es mi identidad socio-cultural?

¿Cómo influye mi identidad en el proceso de observador u observadora que se observa observar y en mi forma de ver el mundo?

¿Cómo influye mi historia de vida en mi forma de ver el mundo y en lo que me interesa investigar?

Y, si desean escudriñar aún más, les invito a reflexionar sobre las siguientes interrogantes:

1. ¿Quién soy? ¿Cómo me defino o identifico profesionalmente?

2. ¿Cuál es mi identidad social? ¿Cuál es mi identidad profesional?

3. ¿Cuál es mi visión sobre mundo, la sociedad y el ser humano?

4. ¿De qué manera los aspectos anteriores influyen o no en la selección del tema o temas que estoy investigando o voy a investigar?

5. ¿Cómo ha sido mi experiencia profesional o laboral?

6. ¿Cómo se relaciona la investigación con mi práctica profesional o laboral?

7. En mi práctica académica, profesional o laboral: ¿Qué se investiga? ¿Para qué se investiga? ¿Por qué se investiga? ¿Quién o quiénes investigan? ¿Cómo investigan? ¿Cómo se utilizan o van a utilizar los resultados de la investigación?

8. ¿Cuál es mi motivación o mi interés personal por el tema que investigo o voy a investigar? 
9. ¿Cuál es la influencia del medio social, académico, profesional o institucional sobre el tema que investigo o voy a investigar?

10. ¿Cuál ha sido mi experiencia previa con la temática que deseo investigar?

11. ¿Cuáles son mis expectativas y aspiraciones?

12. ¿Cuáles son mis prejuicios o creencias en torno al tema de estudio?

\section{8. ¿Y después de esta reflexión autobiográfica? Nuevos retos...}

Después de realizar el viaje y valorar "mis provisiones", analizo nuevos retos y decido si me interesan o no y, si estoy dispuesta o dispuesto a asumirlos, o no. Queda abierta la opción para proponer otros...

1. ¿Cuáles son los nuevos desafíos de la educación?

2. ¿Cuáles los nuevos desafíos de la investigación educativa?

3. ¿Qué aportes brindan las últimas investigaciones de la sociología de la educación, las teorías del aprendizaje, la antropología cultural, las neurociencias, de la epistemología educativa, entre otras?

4. ¿Cuáles son las relaciones actuales que caracterizan el vínculo entre la educación y la revolución tecnológica que está moldeando una nueva configuración social y cultural?

5. ¿Cómo se caracteriza el sujeto educativo actual en relación con el sujeto educativo de la modernidad?

6. ¿Cómo abandonar la idea moderna de la homogeneidad pedagógica y zambullirse en la incertidumbre de una pedagogía del caos, más ajustada a los tiempos que corren?

7. ¿Cuál es el nuevo sujeto educativo para la sociedad global?

8. ¿Cómo enfrentar el "analfabetismo político" y la percepción ingenua del mundo, de la sociedad y de la educación?

9. ¿Cómo complejizar la noción de contexto para darle movimiento y dinamismo a su complejidad?

10. ¿Qué significado tiene el tiempo para nosotras y nosotros?

\section{A manera de síntesis}

En primer lugar, considero importante retomar parte del epígrafe que encabeza este artículo, específicamente donde Rojo (2006, párr. 1) insiste en que: “(...) Necesitamos un cambio de visión, una nueva forma de observar, [puesto que] ya no sirven los espejuelos mecanicistas, es hora de un punto de vista diferente que acepte la incertidumbre como el principio, como el fin (...)". En consecuencia, en este artículo hice énfasis en que para lograr ese cambio de visión es urgente ejercitar una nueva forma de observar la realidad-realidades. Nueva forma de observar que está mediada por nuestra identidad, por nuestra historia de vida, por nuestros valores, prejuicios, gustos, encuentros y desencuentros. Por ello apelé a la necesidad de iniciar un proceso de reflexión sistemático y constante sobre: ¿Cuáles son nuestras responsabilidades en el proceso de construcción de identidades? ¿Quién es el sujeto de la educación? ¿Cuán inclusivas son nuestras nociones de sujeto educativo y la del sujeto empírico? ¿Cuál es la relación sujeto-objeto? ¿Cuál es el aporte de la subjetividad? ¿Cuál es la potencialidad que tiene la autobiografía intelectual como fundamento 
epistémico? ¿Por qué centrar la atención en las personas, en su historia, sus relaciones sociales y su ambiente, como sujetos y no solo como objetos de estudio, es un movimiento epistémico, político y ético? ¿Por qué las investigadoras y los investigadores cualitativos no solo deben comprender quiénes son, sino que también deben explicitarlo?

En segundo lugar, la predisposición biológico-genética de una persona, su historia a lo largo de las diversas etapas de su desarrollo y crecimiento, sus estructuras y procesos cognitivos y afectivos, su interrelación con la Otredad, su sistema de vida, sus creencias, sus valores, sus prejuicios y su interacción con su entorno ambiental y natural influyen en lo que la persona es, y en todo lo que hace. En síntesis, en la forma como cada sujeto-persona piensa, aprende, construye, conoce e investiga.

En tercer lugar, señalé que la autobiografía intelectual tiene una gran potencialidad para el auto-análisis y como medio para facilitarnos el tránsito de sujetos del sentido común y del saber-hacer profesional, a la de sujetos epistémicos. Como también para comprender el tono y el enfoque o dirección de un proceso investigativo.

En cuarto lugar, con este artículo pretendo abrir otras opciones, por ello lo concebí como una provocación, una ruptura o una invitación para reflexionar sobre la temática expuesta, de tal forma que he decidido incluir la siguiente cita de Erdheim con el propósito de invitarle, a usted SUJETO-PERSONA, a decidir si desea aprovechar la oportunidad de dar un giro a la dirección de su vida, es decir, a su práctica como investigadora o investigador o si decide continuar llevándola como hasta ahora.

Las palabras ${ }^{13}$ constan de material fonético que ciertamente puede ser retenido por la grabadora, pero que despierta en quien escucha una reacción inmediata que condiciona la posterior secuencia de la conversación. Esta reacción es subjetiva y resulta tanto de la praxis de vida actual, como del horizonte de expectativas del escucha. Lo que él [o ella] comprende contribuye a transformar tanto las experiencias actuales como las expectativas que en ella se fundan. Por otra parte, al hablar, las palabras y frases desencadenan recuerdos que son huellas de aquello que para él [o para ella] tiene sentido hoy. En la conversación, que conecta entre sí al recuerdo y la aportación de sentido, surge la oportunidad de dar un giro a la dirección de la vida o decidir seguir llevándola como hasta entonces. Erdheim (2003, p. xi)

\section{Referencias bibliográficas}

Berger, P. y Luckmann, T. (1987). La construcción social de la realidad. Buenos Aires, Argentina: Amorrutu.

Chavarría-Rojo, A. (2006). El mito de la realidad. Recuperado de http://alexchrojo.blogspot. com/2006/03/por-qu-el-mito-de-la-realidad-un-ao-y.html

Da Silva, T. T. (2001). Espacios de identidad. Nuevas visiones sobre el curriculum. España: Octaedro.

13 Las palabras destacadas con negrita son de mi entera responsabilidad. 
Diker, G. y Terigi, F. (1997). La formación de maestros y profesores: hoja de ruta. Buenos Aires, Argentina: Paidós.

Erdheim, M. (2003). La producción social de la inconsciencia. Una introducción al proceso etnopsicoanalítico. México: Siglo Veintiuno Editores.

Fonseca, A. L. (2005). Del Cielo a la Tierra (Ensayo sobre antinomias, desencuentros y dualismos). San José, Costa Rica: Editorial Costa Rica.

Gadamer, H.-G. (1976). El círculo hermenéutico y el problema de los prejuicios. Universidad de Chile: Teoría.

Girardi, G. (1977). Por una pedagogía revolucionaria. Barcelona: Laia

Gurdián, A. (2010). El paradigma cualitativo en la investigación socio-educativa. San José, Costa Rica: EUCR.

Magendzo, A. (2004). Alteridad, componente fundante de una educación ciudadana. Recuperado de http://www.educarchile.cl/Portal.Base/Web/VerContenido.aspx?ID=77979

Miglianelli, A.(s.f.).De la ecología a la ecología social. Red de Ecología Social.Biblioteca de Ecología Social. Recuperado de: http://www.ecologiasocial.com/biblioteca/MiglianelliEcologiaSocial. $\underline{\mathrm{htm}}$

Schutz, A. (1974). Estudios sobre teoría social. Buenos Aires, Argentina: Amorrortu Editores. 